InterAção | 25

\title{
AMÉRICA LATINA: AMENAZAS Y CALIDAD DE LA DEMOCRACIA EN EL SIGLO XXI
}

Carlos Andrés Jiménez Navarro ${ }^{1}$

\section{Resumen}

La primera década del siglo XXI en América Latina ha trascurrido en la mayoría de los países bajo el control de gobernantes elegidos democraticamente, lo que no indica necesariamente que la democracia este plenamente consolidada, sino que aun se encuentra en proceso de construcción. Por lo tanto, en medio del desarrollo de los procesos democráticos en la región, es necesario establecer factores que se conviertan en punto de partida para evaluar la calidad de las democracias; un primer factor que permite determinar de manera general la calidad de las democracias es la justicia, entendida como: La democracia opera con justicia, contenido de justicia dentro de las democracias y la democracia como herramienta para identificar injusticias. Así mismo, se determinaron tres aspectos identificados como amenazas latentes y permanentes para las democracias en la región: 1. Desigualdad e inequidad. 2. Participación e inclusión de la ciudadanía. 3. Personalización de la democracia.

Palabras Clave: Democracia, consolidación, calidad de la democracia, ciudadanía, justicia, desigualdad, elecciones, poder, mecanismos, instituciones.

1 Estudiante Maestría en Asuntos Internacionales, Universidad Externado de Colombia, Bogotá. 
26 | InterAção

\section{Abstract}

The first decade of the century in Latin America has elapsed in most countries under the control of democratically elected governments, which does not necessarily indicate that this fully consolidated democracy, but that is still under construction. Therefore, in the middle of the development of democratic processes in the region, it is necessary factors to become a starting point for assessing the quality of democracy, a first factor that determines the overall quality of democracies is justice, understood as democracy operates with fairness, justice content within democracies and democracy as a tool to identify injustices. It also identified three areas identified as latent and permanent threat to democracies in the region: 1 . Inequality and inequity. 2. Participation and inclusion of citizenship. 3. Customizing democracy.

Keywords: Democracy, consolidation, quality of democracy, citizenship, justice, inequality, elections, power, machinery, institutions.

El Siglo XXI en América Latina se desarrolla sobre el objetivo de lograr la consolidación del sistema democrático, teniendo en cuenta los antecedentes de las dictaduras militares en los años $70 \mathrm{y}$ 80 y las transiciones democráticas en los años 90; lo cual representó cierto optimismo sobre la búsqueda de una mayor participación e inserción de las mayorías dentro de la participación política "Sin una tendencia idealista una democracia no nace, y si nace, se debilita rápidamente. Más que cualquier otro régimen político, la democracia va contra la corriente, contra las leyes inerciales que gobiernan los grupos humanos." (SARTORI, 1991. p. 118). 
El logro de esta consolidación está sujeto a la definición misma de democracia "La democracia es un régimen político cuyo funcionamiento está mediado por los tipos de articulación entre sociedad, sistema político y Estado existentes en una formación social en un momento histórico determinado" (ZAPATA, 2001. p. 35). Lo anterior necesariamente condiciona tanto la forma como el grado de desarrollo de la democracia dentro de cada país, teniendo en cuenta que son diferentes entre sí y por ende las características y particularidades de cada democracia difieren de los demás.

Al mismo tiempo que se presentaban los procesos de transición democrática en América Latina, se experimentaban cambios significativos en cuanto al modelo económico desarrollado, - modelo neoliberal- lo que expuso a la región frente la globalización económica y la competencia en mercados internacionales - sin contar con suficiente eficiencia y competitividad-; dichos cambios profundizaron los niveles de desigualdad e inequidad dentro de la población latinoamericana.

Este panorama que presenta el siglo XXI genera una paradoja dentro de la región, entre contar con sistemas democráticos (elecciones periódicas, libres, competitivas y trasparentes) — salvo alguna excepción, en todos los países sus gobernantes fueron elegidos- y por otro lado un notable descontento de las mayorias frente la creciente desigualdad y exclusión a la cual son sometidas las sociedades. A pesar de existir esta paradoja dentro del contexto democrático latinoamericano y aunque dentro de la primera década han existido crisis cuyo objetivo ha sido desestabilizar los regímenes democráticos como fueron los intentos de golpe tanto en Venezuela como en Honduras 
en 2002 y 2009 respectivamente; América Latina presenta un sistema democrático estable toda vez que aunque existen ciertas fallas dentro de las instituciones estas se han mantenido durante las dos últimas décadas, lo anterior sumado al incremento en los índices de desigualdad y malestar social no han debilitado la vocación democrática de la región sino por el contrario han buscado evitar y blindar la región del regreso de gobiernos autoritarios.

Dentro de este fortalecimiento del sistema democrático en los países de América Latina, ha sido un factor fundamental las elecciones, ya que estas definen el modo como se accede al poder y la forma como éste es ejercido; esta importancia refleja que las democracias latinoamericanas son en cierto grado "democracias enraizadas, que consisten en la interdependencia de cinco regímenes parciales: (régimen electoral, derechos políticos, derechos civiles, control horizontal de poderes y capacidad efectiva para gobernar)" (MERKEL, 2008. p. 21).

\section{Calidad de la democracia}

Teniendo en cuenta el desarrollo democrático en América Latina desde finales del Siglo XX se hace necesario pasar de una evaluación no solo del funcionamiento mismo de las democracias a una evaluación de la calidad de las mismas; la mayor dificultad que surge frente esta evaluación es, ¿Calidad de la democracia respecto de qué?, es decir establecer un valor de referencia dentro de las democracias para determinar, sí la democracia en cierto país es buena o no.

El concepto mismo de calidad surge y tiene un uso más frecuente en disciplinas como la administración o la producción de algún 
tipo de bien, ya que implica que tan bueno o malo es cierto producto frente unos parámetros de comparación, por lo general de tipo cualitativo; es allí donde aplicar el concepto de calidad de la democracia y ante todo establecer las condiciones o atributos de calidad para la misma puede variar de un estudio o investigador a otro, como de un país así como la metodología misma para cuantificar los resultados obtenidos. (El presente artículo no evalúa ningún tipo de metodología utilizada para evaluar la calidad de la democracia en América Latina, únicamente busca determinar algunas condiciones mínimas, que sirvan como punto de partida para señalar si existe o no algún grado de calidad en la democracia).

La principal dificultad en el análisis en cuanto la calidad de la democracia es que este depende de la definición misma de democracia y que es posible "confundir la calidad de una democracia con el nivel de democratización de un régimen político. Sin embargo, los análisis de calidad sólo pueden aplicarse a aquellas sociedades que han asumido un mínimo grado de democratización, esto es, aquellas que cumplen los requisitos elementales de una democracia" (MORLINO, 2009. p. 26).

Como punto de partida en la evaluación de la calidad de la democracia es necesario tener en cuenta - como mínimo- el elemento de la justicia; discriminada en tres aspectos fundamentales:

1.La democracia opera con justicia: entendiendo que el procedimiento o funcionamiento mismo de la democracia debe contener niveles de justicia, de tal manera que ofrezca las condiciones necesarias para satisfacer como mínimo las garantías que propone el concepto de poliarquía de Robert Dahl: 
30 | InterAção

(...) libertad de asociación, libertad de expresión, libertad de voto, elegibilidad para el servicio público, derecho de los líderes a competir en busca de apoyo, diversidad de fuentes de información, elecciones libres e imparciales e instituciones que garanticen que la política del gobierno dependa de los votos y demás formas de expresar las preferencias (DAHL, 2002).

Desde esta perspectiva de análisis, la calidad democrática dentro de la región no es el resultado del proceso sino las características dentro de las cuales se desarrolla el mismo.

2. Contenido de justicia dentro de las democracias: las democracias por sí mismas deben propender por la implementación de procedimientos justos que permitan a los diferentes actores - instituciones, ciudadanos y partidos políticos- participar en condiciones de libertad e igualdad. Del contenido de justicia que presenta la democracia depende en gran parte tanto el mantenimiento y fortalecimiento de la misma - traducido necesariamente en una mejora de la calidad en la democracia - por lo tanto esta labor no exige ningún tipo de esfuerzo extraordinario ni por parte de gobiernos, ni de las sociedades; únicamente requieren de un compromiso constante frente la importancia de mantener el régimen y lo que significa estar inmerso dentro del mismo; parte de lo que pueden - y deben - hacer los gobiernos, ya en 1941 el Presidente Franklin Delano Roosevelt lo manifestaba en su Discurso de las Cuatro Libertades:

No hay nada misterioso respecto de los cimientos de una democracia saludable y fuerte. Las cosas básicas esperadas por nuestro pueblo de sus sistemas político y económico son simples.

Ellas son: 1. La igualdad de oportunidad para los 
InterAção | 31

jóvenes y los demás. 2. Un empleo para los que pueden trabajar. 3. La seguridad (social) para los que la precisan. 4. El fin del privilegio especial para unos pocos. 5. La preservación de las libertades civiles para todos. 6. La participación en los frutos del progreso científico, en un estándar de vida constantemente creciente y ampliamente compartido.

Éstas son las cosas sencillas y básicas que nunca deberían perderse de vista en el tumulto y complejidad increíble de nuestro mundo moderno. La fuerza interior y duradera de nuestros sistemas económico y político depende del grado en que cumplen con estas expectativas (ROOSEVELT, 1941).

3. La democracia debe identificar las injusticias: si bien la calidad democrática se puede medir más por los procedimientos y las formas que por los resultados, los regímenes democráticos deben estar en la capacidad de identificar las injusticias que se presentan dentro del proceso y proponer acciones que permitan la corrección de las mismas de manera eficiente y oportuna, ya que el no hacerlo la expone a mayores en riesgos - estos riesgos para la región se clasifican dentro del presente artículo como amenazas de la democracia-

\section{Amenazas de la democracia}

Más allá de la euforia causada por los evidentes avances presentados en cuanto el desarrollo democrático en tan corto tiempo - 20 años-, no se puede desconocer la problemática misma del proceso de consolidación democrática y las amenaza a las cuales está expuesta, es por eso que tanto los gobiernos como las sociedades deben velar por el mantenimiento y fortalecimiento del sistema, tal como lo expresa el 
Director del Informe: La Democracia en América Latina: hacia una democracia de ciudadanas y ciudadanos, en el marco de la estrategia del Programa de las Naciones Unidas para el Desarrollo (PNUD):

Los déficit, las lagunas, las asechanzas que se ciernen sobre nuestras democracias no deberían llevarnos a olvidar que hemos dejado atrás la larga noche del autoritarismo. No hay malestar con la democracia, pero hay malestar en la democracia y para resolverlo es indispensable hacer uso del instrumento más preciado que ella nos brinda: la libertad. Libertad para discutir lo que molesta, lo que algunos preferirían que se oculte... libertad para saber que un sistema que es casi un sinónimo de igualdad, convive con la desigualdad más alta del planeta (CAPUTO, 2004. p. 21-22).

En este sentido, es posible identificar tres factores que son considerados como amenazas permanentes para las democracias en la región: 1. Desigualdad e inequidad. 2. Participación e inclusión de la ciudadanía y 3. Personalización de la democracia; por lo tanto, en la medida en que estos factores sean tratados y neutralizados, los riesgos inherentes al sistema democrático serán reducidos, de la misma manera se fortalecerá el proceso democrático mejorando los indicadores de calidad de las democracias — sin importar cuales sean, es decir que son transversales a cualquier democracia o cualquier indicador de calidad de la misma-.

\section{Desigualdad e inequidad}

Tal como se ha citado anteriormente, la paradoja entre democracia - desigualdad e inequidad — que se hace evidente al revisar los 
índices de pobreza en la región-, obliga a reformular el replanteamiento de: ¿Cuál puede ser en realidad el modelo económico exitoso, para que democracia y desarrollo económico — general— sea posible?; sobre este cuestionamiento Friedrich A. Von Hayek en la década de los 70 del siglo XX manifestaba:

El advenimiento de la democracia en el pasado siglo [XIX] produjo una alteración radical de la actitud del ciudadano ante el poder estatal. Si, durante siglos, los esfuerzos de la humanidad se habían dirigido a la limitación del poder del gobernante súbitamente empezó a pensarse que el hecho de que el gobierno hubiera quedado sometido al control de la mayoría hacía innecesario mantener sobre él cualquier limitación, por lo que cabía impunemente abandonar todas las salvaguardias constitucionales hasta entonces erigidas. Surgió así la moderna democracia ilimitada; y es está, (...) la que constituye el problema (HAYEK, 1985.p. 8).

Ahora bien, es en este aspecto donde los gobiernos de América Latina no deben, por una parte, regresar al paternalismo estatal en el cual las sociedades dejan de ser competitivas - más aun donde la economía mundial se encuentra en pleno proceso de globalización-, pero de igual manera se hace necesario eliminar aquellos privilegios que se otorgan a las elites que históricamente han detentado el poder.

Una forma en que el Estado y los gobierno puede lograr una reducción en los niveles de desigualdad e inequidad - $-\mathrm{y}$ de esta manera fortalecer la Democracia- es mediante el respeto y regulación de las condiciones del mercado en cuanto: la competencia, facilidades y oportunidades de acceso, seguridad jurídica y cambiaria; de esta 
manera la democracia y los movimientos democráticos se convierten en medios para buscar mejoras en el bienestar de las sociedad, ratificando que "uno de los objetivos principales de los movimientos democráticos ha sido buscar compensación en la esfera política para los efectos de las desigualdades en la economía y en la sociedad" (BEITZ, 1989. p. 16).

\section{Participación e inclusión de la ciudadanía}

Paralelamente al proceso de transición y consolidación democrática en América Latina se ha desarrollado y tomado cada vez más importancia el concepto de ciudadanía, reconocida no solo como actor fundamental dentro de la lucha por el retorno democrático sino como "un arma crucial no sólo en las luchas en contra de la exclusión y la desigualdad económica y social, sino mas, más importante aún, en la ampliación de las ideas dominantes de la política en si misma... ha sido un paso esencial hacia la 'democratización de la democracia' o hacia su intensificación”(DAGNINO, 2008. p. 194-195).

La democracia desde su definición básica de una forma de acceso al poder, tiene que vincular al ciudadano ya que sobre éste recae la responsabilidad política de quién lo representa y toma las decisiones dentro del estado; la fragilidad del régimen democrático es a su vez otra paradoja ya que por una parte democratiza el reclamo social sobre la función del estado y el gobierno en cuanto su participación en las decisiones haciendo evidente que los "regímenes son institucionalmente frágiles, porque sus líderes políticos no están realmente preocupados por la participación política o la movilización de los actores 
sociales para contribuir a la formación de la representación, sino en la medida en que se garantice el cumplimiento de las formas electorales" (ZAPATA, 2001. p. 47).

En la medida en que las sociedades y la participación ciudadana se hagan más incluyentes, permitan la participación de la ciudadanía sin ningún tipo de exclusión se fortalecerá el sistema democrático teniendo en cuenta que "afianzar la democracia [...] pasa necesaria e indispensablemente por la sociedad civil, sobre todo por las posibilidades de volver visibles a los invisibles. Esto simplemente porque no pueden existir derechos de ciudadanía si no son para todas y todos. Derechos para algunos, por más numerosos que éstos sean, no son derechos, son privilegios. Ciudadanía es expresión de una relación social que tiene como presupuesto a todos, sin excepción”. (GRZYBOWSKI, 2004).

Es el sistema democrático mismo el que debe crear y ofrecer los mecanismos institucionales - operativos y eficientes - que permitan el control del poder, es decir el establecer un control de abajo hacia arriba y entre iguales sobre la base del interés general y la capacidad de reacción frente los abusos - o potenciales abusos- de quienes en determinado momento detenten el poder.

\section{Personalización de la democracia}

Dentro de las distorsiones que han enfrentado los sistemas democráticos durante el Siglo XXI en América Latina, una de las más visibles - en la actualidad - es el fenómeno del surgimiento de personajes que se autoproclaman como la personificación de la demo- 
cracia y por lo tanto salvación de cada uno de los pueblos, lo cual se convierte en una de sus amenazas principales.

Esta amenaza atenta de manera directa contra la esencia misma de la democracia — en cuanto su definición — afectando cada uno de sus componentes: elecciones libres (como consecuencia de la personalización del poder, crean aparatos burócratas y clientelistas para su propio interés), elecciones periódicas ( modifican las constituciones nacionales con el fin de ampliar, prorrogar y hasta perpetuar su periodo en el poder), elecciones competitivas (desprestigian la oposición, destruyen el sistema de partidos y polarizan las sociedades), elecciones transparentes (como consecuencia de la concentración de poder manipulan las elecciones y cuentan con apoyos de todo tipo para la satisfacción de sus intereses).

Estos gobernantes quienes utilizan a su favor las amenazas citadas anteriormente — desigualdad económica e inclusión ciudadana- más la debilidad institucional propia de este proceso de consolidación democrática, padecen del Síndrome Hybris - enfermedad de la arrogancia, o borrachera de poder-, definida por el Neurólogo y político Británico David Owen como "una patología que afecta a determinados políticos con alta responsabilidad de gobierno, que se inicia desde una megalomanía instaurada y termina en una paranoia acentuada. Una persona más o menos normal de repente alcanza el poder y al principio le asalta la duda de si será capaz de desarrollar esa actividad engrandecida de la política. Pero pronto sale de la duda porque empieza a merodearle una legión de incondicionales que no cesan de felicitarle, darle palmaditas en la espalda y recibir halagos, reconociéndole su valía” (OWEN, 2010). 
InterAção | 37

Los principales síntomas de dicha patología presentes en la actualidad latinoamericana son:

a) Transforma las dudas en seguridades, y comienza a pensar que todo lo bueno que sucede es mérito propio;

b) Cree totalmente en todo lo que hace y dice y el iluminismo se apodera de él. Su mundo se hace amplio y el de los demás estrecho el suyo ilimitado y el de los demás, casi inexistente;

c) Se convierte en infalible y se cree insustituible;

d) Todo aquel que no asume sus ideas o las rebate, se vuelve un enemigo personal que pierde todos sus derechos.

La mejora en los índices de calidad de la Democracia en América Latina es posible si se realizan acciones — no solo por parte de los Estados y los Gobiernos sino de la ciudadanía en generaldireccionadas a superar las amenazas mencionadas anteriormente; lo importante es detectar y tomar acciones de manera oportuna frente los síntomas que presentan las democracias de la región frente estas amenazas, solo así se podrá continuar con su protección y garantía para el futuro.

De igual manera es fundamental dentro del proceso de consolidación democrática comprender que no es el sistema democrático el que conduce el país, sino son los ciudadanos y el estado los que conducen la democracia, dentro de sus dinámicas propias - reconociendo que existen diferencias históricas importantes en cada país-; es por eso que la democracia no es un sistema que sea importado o exportado, su desarrollo depende en gran parte del desarrollo mismo de las sociedades y de la participación activa de la sociedad civil en la toma de decisiones; es la articulación entre Ciudadanía - Gobierno - 
38 | InterAção

Partidos Políticos quien define y establece el conjunto de herramientas que son y serán utilizadas para lograr la consolidación democrática, limitando el poder de los gobernantes y de esta manera alejando el autoritarismo; logrando así una democracia con altos indicadores de calidad sostenibles en el tiempo.

\section{REFERENCIAS}

BEITZ, Charles. Igualdad política: Un ensayo sobre la teoría democrática. Princeton: Editorial de la Universidad de Princeton, 1989.

CAPUTO, Dante. Libertad, democracia y política. In: La democracia en América Latina: hacia una democracia de ciudadanas y ciudadanos. Ed. Fernando Esteves. Buenos Aires, Aguilar, Altea, Taurus, Alfaguara, 2004. pp. 21-23.

DAGNINO, Evelina. Los significados de ciudadanía en América Latina. In: Estado, democracia y populismo en América Latina. Ed(s). Adolfo Chaparro, Carolina Galindo y Ana María Sallenave. Bogotá: Editorial Universidad del Rosario, 2008. pp. 194-227.

DAHL, Robert. La poliarquía: participación y oposición. Madrid: Tecnos, 2002.

GRZYBOWSKI, Cándido. Democracia, sociedad civil y política en América Latina: notas para un debate. Texto preparado para PRODDAL. In: PNUD. La democracia en América Latina. Hacia una democracia de ciudadanas y ciudadanos: Contribuciones para el debate. Buenos Aires: Aguilar, Altea, Taurus, Alfaguara, 2004.

HAYEK, Friedrich. Democracia, Justicia y Socialismo. Madrid: Unión Editorial, 1985. 
MERKEL, Wolfgang. Democracias enraizadas y defectuosas. In:

Estado, democracia y populismo en América Latina. Ed(s). Adolfo

Chaparro, Carolina Galindo y Ana María Sallenave. Bogotá: Editorial Universidad del Rosario, 2008. pp. 21-50.

MORLINO, Leonardo. La calidad de la democracia. In: Claves de razón práctica, No. 193: 2009. pp. 26-35.

OWEN, David. En el poder y en la enfermedad. Madrid: Ediciones Siruela, 2010.

ARIAS, Jorge; PRIESS, Frank. Índice de desarrollo democrático de América Latina. México D.F: Fundación Konrad Adenauer, 2011. Disponível em: $<$ www.idd-lat.org $>$.

ROOSEVELT, Franklin Delano. Discurso de las Cuatro Libertades. Discurso presentado en, Enero 06, Washington D. C, Estados Unidos, 1941.

SARTORI, Giovanni. Democracia. In: Revista de Ciencia Política. Vol. 13, No. 1: 1991. p. 118.

TOURAINE, Alain. ¿Qué es la democracia? Buenos Aires: Fondo de Cultura Económica, 1995.

ZAPATA, Francisco. Las perspectivas de la democracia en América Latina. In: Foro Internacional. Vol. 41, No. 163, 2001. pp. 35-62. 
40 | InterAção 